\title{
FAAS Determination of Au and Pd After Selective Preconcentration on Ethylenediamine Silica Material Prepared By the Sol-Gel Method
}

\author{
Mustafa Imamoglu* and Sinem Albayrak \\ Sakarya University, Faculty of Science and Arts, Chemistry Department \\ 54187 Sakarya, Turkey
}

\section{INTRODUCTION}

Gold and palladium are known as precious and noble metals together with the silver (Ag) and platinum $(\mathrm{Pt})$ group metals, including ruthenium $(\mathrm{Ru})$, rhodium $(\mathrm{Rh})$, palladium (Pd), osmium (Os), iridium (Ir), and platinum (Pt) (1-3). They are widely used in a number of areas such as the electronic industries, for jewelry, etc. (4-6). Moreover, Pd, together with Pt and $\mathrm{Rh}$, have been used in auto-catalytic converters to reduce emission of harmful species in exhaust gases $(6,7)$. Precious metals such as Au and Pd are often found at very low concentration levels in geological, metallurgical, and environmental samples (such as water and wastewater) $(8,9)$; thus, the development of analytical procedures for their trace level determination is very important.

The determination of gold (Au) and palladium $(\mathrm{Pd})$ in ore, metallurgical or environmental samples has been performed by flame and graphite furnace atomic absorption spectrometry (FAAS and GFAAS), inductively coupled plasma mass spectrometry (ICP-MS), and inductively coupled plasma atomic emission spectrometry (ICP-AES) (3,7, 10,11). Flame atomic absorption spectrometry has been widely used in analytical chemistry laboratories because of its relatively low cost and ease of operation $(12,13)$. However, the use of FAAS is limited due to two main problems: (a) lower

*Corresponding author. E-mail: imamoglu@sakarya.edu.tr Tel: +902642956053

Fax: +902642955950

\section{ABSTRACT}

In this study, a selective preconcentration method for trace $\mathrm{Au}(\mathrm{III})$ and $\mathrm{Pd}(\mathrm{II})$ ions based on their sorption on modified silica material is presented. The modified silica with ethylenediamine was prepared using the sol-gel technique and is characterized by elemental analysis and FT-IR spectrometry. Au(III) and Pd(II) ions were quantitatively retained on the column at slightly acidic conditions, loaded with modified silica, and then successfully eluted with a solution of thiourea $1 \%(\mathrm{~m} / \mathrm{v})$ in $0.1 \mathrm{M}$ hydrochloric acid. The metal ions in the eluate were determined by flame atomic absorption spectrometry. The effects of different factors, such as $\mathrm{pH}$ of the sample solution, sample volume, flow rate of sample solution, type of eluent and matrix content of the sample solution on preconcentration, were examined to obtain optimum conditions.

The recoveries for Au(III) and Pd(II) ions under optimum preconcentration conditions were $99 \pm 2$ and $98 \pm 2 \%$ at the $95 \%$ confidence level, respectively. The analytical detection limits of $\mathrm{Au}$ and Pd were 0.20 and $0.21 \mu \mathrm{g} \mathrm{L}^{-1}$, respectively. The presented method was validated by the analysis of certified reference platinum ore (SARM7B). The obtained results agreed with the certified values.

concentration of analyte ions than the limit of detection (LOD) and (b) the matrix effects of the sample solution $(14,15)$. To increase analyte concentration and eliminate matrix ions, a separation and preconcentration step is required prior to FAAS measurement. This step can eliminate part or all of the interfering ions in the sample. A number of methods, including sorption, precipitation, co-precipitation, solvent extraction, flotation, etc., have been used for trace element enrichment (16-25).

Solid phase extraction (SPE) is an effective preconcentration technique based on sorption of the analyte ions on the solid sorbent. It is a widely used method due to its properties, such as simplicity, speed, low cost, and ease of automation (26). The basic principle of SPE is partitioning of the analyte between the sample solution and the solid sorbent phase. SPE of trace metal ions from the solution can be carried out by batch and column techniques. Adsorbed metal ions on the solid phase can be collected into the liquid phase by using a suitable eluent, such as solution of acids, complexing agent, etc. (27-29). In this technique, the sorbent is very important because the performance of the method is directly related to the effectiveness of the sorbent. Hence, current research in SPE has mainly focused on the preparation of novel sorbents and evaluation of their performance (30). Chelating and ion exchange resins are the most suitable sorbents for SPE due to their high selectivity. The resins are mainly prepared by attaching or loading the chelating agents on organic or inorganic support material (29). Silica is most attractive as a solid support because of its excellent properties, such as porosity and broad surface, resistance to heat and acids, no swelling in various solvents, and mechanical strength $(17,31)$. 
Modified silicas can be prepared by grafting or using the sol-gel technique. The sol-gel method is based on hydrolysis and polycondensation of silicon alkoxides in basic or acidic media. This technique is in many ways superior to the grafting method and materials can be prepared in mild reaction conditions, i.e., at room temperature. The surface area, particle size, and organic coverage of the prepared silica can be controlled. Functional chelating groups can also be incorporated into the silica with controlled morphology (32-34).

Silica gel-based chelating resins are prepared by using the organic functional groups, including the $\mathrm{N}$, $\mathrm{O}$, and $\mathrm{S}$ atoms (29). According to the Pearson HSAB theory (35), precious metal ions can interact with nitrogen and/or sulfur atoms.

The chelating resins containing $\mathrm{N}$ atoms have some advantages for the preconcentration of gold and palladium. Firstly, the resins act as anion exchanger at acidic conditions by protonation of the nitrogen atom. While gold and palladium can be adsorbed as an anionic chloro complex on the resin, base metal ions cannot be adsorbed, so that gold and palladium could be preconcentrated and separated from the base metal ions. Secondly, adsorbed gold and palladium ions can be easily eluted because these ions generally cannot be adsorbed strongly on the resin. For enrichment of trace noble metal ions, several solid sorbents bearing $\mathrm{N}$ atoms have been reported in the literature $(1,11,36-44)$. But our literature survey has shown that no study has been published about the preconcentration of Pd(II) and Au(III) on ethylenediamine-silica material prepared by the sol-gel method.

The present study was performed to evaluate the preconcentration ability of ethylenediamine silica (EDA-SIL) synthesized by the sol-gel technique in order to separate and preconcentrate trace $\mathrm{Au}(\mathrm{III})$ and Pd(II) ions from aqueous solution by using the column SPE technique. EDA-SIL was characterized by infrared spectroscopy and $\mathrm{C}, \mathrm{H}, \mathrm{N}$ elemental analysis. The column SPE method was optimized by investigating effective parameters, including $\mathrm{pH}$, flow rate, volume of the sample solution, and eluent type and concentration. The effect of some co-existing metal ions present in aqueous solutions was also studied. The optimized method was validated by determining the Pd concentration in a certified reference ore sample.

\section{EXPERIMENTAL}

\section{Instrumentation}

IR spectra of modified and unmodified silica gels were obtained from $\mathrm{KBr}$ pellets by using a Shimadzu FT-IR spectrometer (Kyoto, Japan). Elemental analysis of the modified silica was carried out at Butal-Tubitak Test and Analysis Laboratory, Bursa, Turkey, using a Costech ECS4010 elemental combustion system.

Flame atomic absorption spectrometry (Shimadzu AA6701F, Kyoto, Japan) was used for the determination of gold and palladium metals. The instrumental parameters were used as per manufacturer's recommendations and are listed in Table I. A deuterium lamp was used for background correction. The flame type was air-acetylene. The palladium and gold wavelengths were 244.8 and $242.8 \mathrm{~nm}$, using a slit width of $0.5 \mathrm{~nm}$, respectively.

\section{Atomic Apectroscopy 1 Vol. 33(1), Jan./Feb. 2012}

The $\mathrm{pH}$ values of the solutions were adjusted by adding $\mathrm{HCl}$ and $\mathrm{NaOH}$ solutions and controlled with a Schott CG840 pH meter (Schott AG, Mainz, Germany).

\section{Standard Solutions and Reagents}

Spectroscopic grade standard solutions of $\mathrm{Au}$ and Pd were used and diluted to the desired concentration with deionized water. Deionized water (chemical resistivity: $18 \mathrm{M} \Omega \mathrm{cm}^{-1}$ ) was used throughout the experiments. Tetraethyl orthosilicate (TEOS), 3-(2-aminoethylamino)propyltriethoxy silane, methanol, and ethanol (Merck KGaA, Darmstadt, Germany) were used without further purification. All other chemicals used were of analytical reagent grade.

\section{Synthesis of Ethylenediamine- Silica Material}

Ethylenediamine-silica material was prepared using a modified procedure of the sol-gel technique described in the literature (45-48). A $5.0 \mathrm{~mL}$ amount of tetraethyl orthosilicate (TEOS), $5.4 \mathrm{~mL}$ of ethanol, and $1.6 \mathrm{~mL}$ of $1 \mathrm{M} \mathrm{HCl}$ solution were mixed for 30 minutes with a magnetic stirrer. Simultaneously, in another beaker $(100 \mathrm{~mL})$, $0.614 \mathrm{~mL}$ of 3-(2-aminoethylamino) propyltriethoxy silane and $5.0 \mathrm{~mL}$ of $1.57 \mathrm{M} \mathrm{HCl}$ solution were mixed and stirred for 30 minutes. These two solutions were mixed, put into one beaker $(100 \mathrm{~mL})$, and stirred for 30 minutes. The sol was left standing for two weeks under ambient temperature. Then, the material was dried for three days at $60^{\circ} \mathrm{C}$ and for one day at $80^{\circ} \mathrm{C}$. The obtained

TABLE I

FAAS Conditions for the Measurement of Au and Pd

\begin{tabular}{cccc}
\hline Analyte & Wavelength $(\mathrm{nm})$ & Slit Width $(\mathrm{nm})$ & Lamp Current $(\mathrm{mA})$ \\
\hline $\mathrm{Au}$ & 242.8 & 0.5 & 12 \\
$\mathrm{Pd}$ & 244.8 & 0.5 & 10 \\
\hline
\end{tabular}


material was ground and sieved and repeatedly washed with deionized water (nearly $200 \mathrm{~mL}$ ) and methanol (nearly $50 \mathrm{~mL}$ ). Then, the EDA-SIL was dried at $60^{\circ} \mathrm{C}$ and a particle size of 63-210 $\mu \mathrm{m}$ was used throughout the study. The proposed structure of EDA-SIL is shown in Figure 1. A blank silica was also prepared by using the same method without addition of silane hydrolysate.

\section{Column SPE Procedure}

A column SPE experiment was performed using a glass column (15 cm length and $0.8 \mathrm{~cm}$ i.d.) filled with $0.3 \mathrm{~g}$ of EDA-SIL. The column was connected to a peristaltic pump in order to percolate the solutions through the sorbent at the appropriate flow rate. A 50-mL sample solution containing individual metal ions of $\mathrm{Au}(\mathrm{III})$ or Pd(II) at the desired $\mathrm{pH}$ value was passed through the column with a certain flow rate $\left(7 \mathrm{~mL} \mathrm{~min}^{-1}\right)$. Then, the adsorbed metal ions on the EDA-SIL were eluted using a solution of thiourea $1 \%(\mathrm{~m} / \mathrm{v})$ in $0.1 \mathrm{M}$ hydrochloric acid. The eluates were collected in a 10 or $5 \mathrm{~mL}$ calibrated flask and the concentration of the metal ions was determined by FAAS. The recoveries of both metal ions were calculated. Blanks and samples were treated in the same manner.

\section{Sample Preparation}

The certified platinum ore SARM $7 B$ (South African Bureau of Standards, Pretoria, South Africa) was used to test the accuracy of the preconcentration method developed in this study. The ore sample ( $2 \mathrm{~g})$

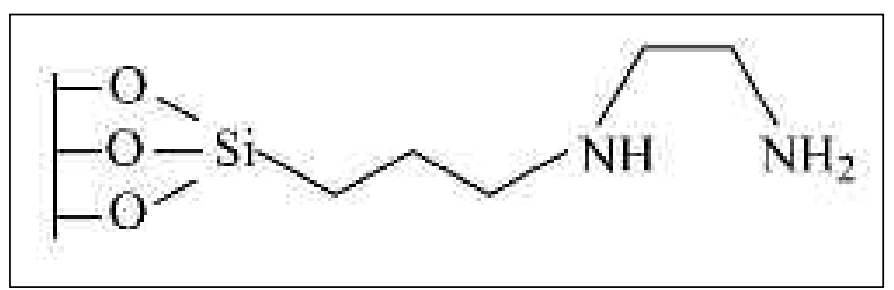

Fig. 1. Proposed structure of ethylenediamine silica material. was digested by using reverse aqua regia as described in the literature $(35,36)$. The $\mathrm{pH}$ of the obtained solution $(50 \mathrm{~mL})$ was adjusted to 1.0 by using a $\mathrm{NaOH}$ solution and the developed method was used for enrichment and determination of the trace Pd(II) ions.

\section{RESULTS AND DISCUSSION}

\section{Characterization of Modified Silica Gel}

Fourier transform infrared spectroscopy (FT-IR) and CHN elemental analysis have been widely used for the characterization of chelating resins. Mid-infrared FTIR spectra of EDA-SIL and blank silica were collected. The blank silica spectrum shows a broad band at $3480 \mathrm{~cm}^{-1}$ with the hydroxyl groups and peaks at $1643,1080,798 \mathrm{~cm}^{-1}$. In addition to these bands, the spectrum of EDA-SIL has N-H and C-H deformation peaks at $1462 \mathrm{~cm}^{-1}$ and $1510 \mathrm{~cm}^{-1}$. The $\mathrm{C}, \mathrm{H}, \mathrm{N}$ elemental analysis results of EDA-SIL were $5.8 \% \mathrm{C}, 2.6 \% \mathrm{~N}, 2.4 \% \mathrm{H}$. The ethylenediamine group content of silica material was calculated based on the $\mathrm{N}$ content and found as $0.93 \mathrm{mmol}$ per gram of the modified silica.

\section{Effect of $\mathbf{p H}$}

The $\mathrm{pH}$ of the aqueous phase is an important parameter in the SPE procedure which affects retention of the analyte ions on the sorbent. In order to evaluate the effect of $\mathrm{pH}$ on the recoveries of $\mathrm{Au}(\mathrm{III})$ and $\mathrm{Pd}(\mathrm{II})$ ions, the $\mathrm{pH}$ of the working solution $(50 \mathrm{~mL})$ was adjusted to a $\mathrm{pH}$ range of $0.5-3.0$, passed through the column at a flow rate of $7 \mathrm{~mL} \mathrm{~min}{ }^{-1}$, then the thiourea $(1 \%, \mathrm{~m} / \mathrm{v})$ in $0.1 \mathrm{M}$ hydrochloric acid was used for the elution of the metals. The recoveries of $\mathrm{Au}$ and $\mathrm{Pd}$ were calculated and the results are shown in Figure 2. Quantitative recoveries (>95\%) were obtained for $\mathrm{Au}(\mathrm{III})$ at the $\mathrm{pH}$ range of 2.0 and 3.0 and for $\mathrm{Pd}(\mathrm{II})$ at the $\mathrm{pH}$ range between 1.0 and 2.5. All subsequent experiments were studied at $\mathrm{pH} 2.0$ for $\mathrm{Au}(\mathrm{III})$ and $\mathrm{pH} 1.0$ for Pd(II). Quantitative recoveries of $\mathrm{Pd}(\mathrm{III})$ and $\mathrm{Au}(\mathrm{II})$ at slightly acidic conditions $(\mathrm{pH} \leq 2)$ enables their separation from base metal ions such as copper and nickel. It is well known that the secondary and tertiary amines will be protonated at this $\mathrm{pH}$ value and could not adsorb base metal ions $(17,36)$.

Various species of $\mathrm{Au}$ (III) and Pd(II) may co-exist depending on the $\mathrm{pH}$ and the chloride concentrations. It has been reported that the 
main species in the $0.1-0.01 \mathrm{M} \mathrm{HCl}$ medium are $\mathrm{AuCl}_{4}^{-}$and $\mathrm{PdCl}_{4}^{-2}$ (49-51). Retention of the anionic species of Pd(II) and Au(III) may occur via electrostatic attraction on the positively charged EDA-SIL surface, and/or via interaction with the electron pair on $\mathrm{N}$ atoms by the chelation mechanism (52-54).

\section{Effect of Eluent Type and Volume}

Applicability of the SPE method depends on the success of the elution step. It is desired that a small volume of eluent can collect the analyte ions from the sorbent surface. For elution of the analytes from the sorbent, various mineral acids, complexing agents, etc., have been used (36). In some cases, a warm eluent solution was needed due to uncompleted elution at ambient temperatures (55).

In this study and for the elution of $\mathrm{Au}$ (III) and Pd(II) adsorbed on EDA-SIL, the solutions of hydrochloric acid and thiourea in hydrochloric acid at various concentrations were examined. The flow of eluent solution through the column was gravitationally performed with flow rates of 1-2 $\mathrm{mL} \mathrm{min}{ }^{-1}$. The obtained recoveries of $\mathrm{Au}(\mathrm{III})$ and $\mathrm{Pd}(\mathrm{II})$ ions with various eluents are listed in Table II. It was found that a $\mathrm{HCl}$ solution (2 M) is not suitable for the elution due to the low recoveries for both analytes. Quantitative recoveries for Au(III) and Pd(II) were yielded by using thiourea ( $1 \%$, $\mathrm{m} / \mathrm{v}$ ) in 0.1 or $1.0 \mathrm{M} \mathrm{HCl}$ solution. All subsequent experiments were conducted by using 10 or $5 \mathrm{~mL}$ of thiourea $1 \%(\mathrm{~m} / \mathrm{v})$ in $0.1 \mathrm{M} \mathrm{HCl}$ solution.

\section{Effect of Sample Flow Rate}

When using the SPE procedure, the duration time prior to the measurement step should be short. The sample flow rate is determined by the kind of interaction between the analytes and the surface of the sorbent. Rapid interaction between them could allow a high flow rate. The effect of sample flow rate of $\mathrm{Au}(\mathrm{III})$ and $\mathrm{Pd}$ (II) recoveries was studied ranging from 3 to $25 \mathrm{~mL} \mathrm{~min}^{-1}$. The results in Table III show that quantitative recoveries were

TABLE II

Effect of Eluent on Recovery of Au(III) and Pd(II) Ions

\begin{tabular}{|c|c|c|c|c|}
\hline \multirow{2}{*}{\multicolumn{2}{|c|}{ Eluent }} & \multirow{3}{*}{$\begin{array}{c}\begin{array}{c}\text { Eluent } \\
\text { Volume }(\mathrm{mL})\end{array} \\
10\end{array}$} & \multicolumn{2}{|c|}{ Recovery (\%) } \\
\hline & & & $\mathrm{Au}(\mathrm{III})$ & Pd(II) \\
\hline \multirow[t]{2}{*}{ Thiourea, $0.1 \%$} & in $0.1 \mathrm{M} \mathrm{HCl}$ & & $77 \pm 2$ & $80 \pm 4$ \\
\hline & in $1.0 \mathrm{M} \mathrm{HCl}$ & 10 & $69 \pm 1$ & $88 \pm 3$ \\
\hline \multirow[t]{3}{*}{ Thiourea, $1.0 \%$} & in $0.1 \mathrm{M} \mathrm{HCl}$ & 10 & $100 \pm 2$ & $98 \pm 2$ \\
\hline & in $1.0 \mathrm{M} \mathrm{HCl}$ & 10 & $98 \pm 2$ & $98 \pm 2$ \\
\hline & in $0.1 \mathrm{M} \mathrm{HCl}$ & 5 & $99 \pm 1$ & $100 \pm 2$ \\
\hline $\mathrm{HCl}, 2.0 \mathrm{M}$ & & 10 & $30 \pm 2$ & $4 \pm 2$ \\
\hline
\end{tabular}

TABLE III

Effect of Flow Rate on Recovery of Au(III) and Pd(II)

\begin{tabular}{ccc}
\hline $\begin{array}{c}\text { Flow Rate } \\
\left(\mathrm{mL} \mathrm{min}^{-1}\right)\end{array}$ & \multicolumn{2}{c}{ Recovery (\%) } \\
\hline 3 & $100 \pm 1$ & Pd(II) \\
7 & $100 \pm 2$ & $99 \pm 1$ \\
15 & $97 \pm 2$ & $98 \pm 1$ \\
25 & $93 \pm 4$ & $97 \pm 2$ \\
\hline
\end{tabular}

\section{Atomic Apectroscopy $\bigcirc$ Vol. 33(1), Jan./Feb. 2012}

obtained for $\mathrm{Au}(\mathrm{III})$ at the flow rates of 3 to $15 \mathrm{~mL} \mathrm{~min}^{-1}$ and for $\mathrm{Pd}(\mathrm{II})$ at 3 to $25 \mathrm{~mL} \mathrm{~min}^{-1}$. The obtained results were found to be higher $\left[15 \mathrm{~mL} \mathrm{~min}^{-1}\right.$ for $\mathrm{Au}(\mathrm{III})$ and $25 \mathrm{~mL} \mathrm{~min}^{-1}$ for Pd(II)] than the recommended flow rates $\left[0.2 \mathrm{~mL} \mathrm{~min}^{-1}\right.$ for $\mathrm{Au}(\mathrm{III})]$ reported in the literature (54). This verifies that the application of high flow rates is an advantage.

\section{Effect of Sample Volume}

It is well known that in column solid phase extraction procedures a high sample volume is important, especially when a high preconcentration factor is needed. Hence, the effect of sample solution volume on the recoveries of $\mathrm{Au}(\mathrm{III})$ and $\mathrm{Pd}(\mathrm{II})$ was studied. In order to evaluate the effect of sample solution, a series of sample solutions were prepared ranging from $50-500 \mathrm{~mL}$ and processed at the optimum conditions. The results listed in Table IV show that the recoveries of the metal ions slightly decreased with an increase in sample volume. However, recovery of Au(III) and Pd(II) was achieved quantitatively at a high sample volume of $500 \mathrm{~mL}$. Using $5 \mathrm{~mL}$ of eluent and a sample solution volume of $500 \mathrm{~mL}$ provided an enrichment factor of 100.

\section{Effect of Matrix Ions}

For the application of this method to real samples, the effects of co-existing ions on the preconcentration were studied. The effects of some metal ions, such as alkali metal ions (potassium and

TABLE IV

Effect of Sample Solution Volume on Recovery of Au(III) and Pd(II)

\begin{tabular}{|c|c|c|}
\hline \multirow{2}{*}{$\begin{array}{c}\text { Sample Solution } \\
\text { Volume (mL) }\end{array}$} & \multicolumn{2}{|c|}{ Recovery (\%) } \\
\hline & $\mathrm{Au}(\mathrm{III})$ & Pd(II) \\
\hline 50 & $100 \pm 2$ & $98 \pm 2$ \\
\hline 100 & $98 \pm 3$ & $99 \pm 2$ \\
\hline 250 & $98 \pm 2$ & $99 \pm 2$ \\
\hline 500 & $95 \pm 3$ & $98 \pm 3$ \\
\hline
\end{tabular}


sodium), alkaline earth metal ions (calcium and magnesium), and heavy metal ions (copper, iron, and nickel), on the recovery of Au(III) and $\mathrm{Pd}(\mathrm{II})$ were investigated. For this purpose, $50 \mathrm{~mL}$ of the gold and palladium solutions $\left(0.4 \mathrm{mg} \mathrm{L}^{-1}\right)$ at the optimum $\mathrm{pH}$ were prepared containing different metal ions at various concentrations. The solutions were passed through the column using the optimum conditions. According to the results given in Table $\mathrm{V}$, the recoveries of $\mathrm{Au}$ (III) and Pd(II) ions were not significantly affected by the matrix elements. Thus, the modified silica material can be used for the preconcentration of gold and palladium from the sample, including matrix ions such as alkali, alkaline earth, and heavy metal ions.

Concentrations of $\mathrm{Ni}(\mathrm{II}), \mathrm{Cu}(\mathrm{II})$, and $\mathrm{Fe}$ (III) metal ions were also determined and found to be $0.08 \pm$ $0.04,1.1 \pm 0.3$, and $0.5 \pm 0.2 \mathrm{mg} / \mathrm{L}$ in the Pd(II) eluates, and $0.1 \pm 0.04$, $1.4 \pm 0.2$, and $6.5 \pm 1.5 \mathrm{mg} / \mathrm{L}$ in the $\mathrm{Au}(\mathrm{III})$ eluates, respectively. The results indicate that only trace amounts of heavy metal ions pass to the eluates and, hence, the modified silica is appropriate for use in the separation $\mathrm{Au}$ (III) and Pd(II) ions from heavy metal ions.

\section{Analytical Figures of Merit}

Precision of the preconcentration of gold and palladium with an EDA-SIL-filled column was investigated at the optimum conditions of a sample volume of $50 \mathrm{~mL}$; amount of each metal, $0.020 \mathrm{mg}$; eluent, $10 \mathrm{~mL}$ thiourea $1 \%(\mathrm{~m} / \mathrm{v})$ in $0.1 \mathrm{M}$

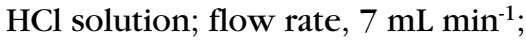
$\mathrm{pH}$ of $\mathrm{Au}$ (III) solution 2.0; and $\mathrm{pH}$ of Pd(II) solution 1.0. For this purpose, eight solutions of each metal ion were percolated through the column. The recoveries of Au(III) and $\mathrm{Pd}(\mathrm{II})$ were found to be $99 \pm 2$ and $98 \pm 2 \%$ at the $95 \%$ confidence level, respectively. The recoveries are quantitative which shows that this method can be reliably used for the preconcentration of $\mathrm{Au}(\mathrm{III})$ and Pd(II) ions.

The stability of the modified silica is very good and its adsorption properties did not change after using it 30 times.

The instrumental detection limits $(3 \sigma)$ of gold and palladium based on three times the standard deviation of the blanks $(n=10)$ were 20.3 and $21.4 \mu \mathrm{g} \mathrm{L}^{-1}$, respectively. The analytical detection limits were calculated by dividing the instrumental detection limits by the enrichment factor (100), resulting in 0.20 and $0.21 \mu \mathrm{g} \mathrm{L}^{-1}$, respectively $(17,56)$.

\section{Application of the Method}

Palladium was determined in certified platinum ore sample SARM $7 \mathrm{~B}$ from The South African Bureau of Standards. The certified and found values (ppm) and the relative error percentages were $1.54 \pm 0.032$, $1.49 \pm 0.04$, and $-3.2 \%$, respectively (see Table VI). Palladium was determined with a low relative error. As can be seen, ethylenediamine silica

TABLE V Effect of Matrix Ions on Recovery of $\mathrm{Au}$ (III) and Pd(II)

\begin{tabular}{lccc}
\hline $\begin{array}{c}\text { Matrix } \\
\text { Ions }\end{array}$ & $\begin{array}{c}\text { Concen- } \\
\text { tration } \\
\left(\mathrm{mg} \mathrm{L}^{-1}\right)\end{array}$ & \multicolumn{2}{c}{ Recovery (\%) } \\
\hline $\mathrm{Na}^{+}$ & 2000 & $98 \pm 1$ & $99 \pm 1$ \\
$\mathrm{~K}^{+}$ & 1000 & $98 \pm 2$ & $99 \pm 1$ \\
$\mathrm{Ca}^{+2}$ & 1000 & $99 \pm 2$ & $99 \pm 3$ \\
$\mathrm{Mg}^{+2}$ & 1000 & $96 \pm 2$ & $95 \pm 3$ \\
$\mathrm{Cu}^{+2}$ & 1000 & $96 \pm 1$ & $99 \pm 3$ \\
$\mathrm{Fe}^{+3}$ & 1000 & $97 \pm 2$ & $96 \pm 4$ \\
$\mathrm{Ni}^{+2}$ & 1000 & $99 \pm 2$ & $97 \pm 3$ \\
\hline
\end{tabular}

material can successfully be used for the preconcentration of palladium from ore samples.

\section{CONCLUSION}

In this study, a novel solid phase extraction (SPE) procedure for the determination of $\mathrm{Au}$ and $\mathrm{Pd}$ by flame atomic absorption spectrometry (FAAS) is presented. It is based on the preconcentration of Au(III) and Pd(II) ions on ethylenediamine silica material prior to the measurement step.

Palladium (II) and gold (III) ions can be quantitatively adsorbed on the ethylenediamine silica material at slightly acidic conditions. At these $\mathrm{pH}$ values, heavy metal ions were not adsorbed on the column, so that separation of $\mathrm{Pd}(\mathrm{II})$ and $\mathrm{Au}$ (III) from the heavy metal ions is feasible. Elution of the adsorbed precious metal ions on the column was easily performed using acidic thiourea solution. The modified silica gel could be used at high flow rates $\left[15 \mathrm{~mL} \mathrm{~min}^{-1}\right.$ for $\mathrm{Au}(\mathrm{III})$ and $25 \mathrm{~mL} \mathrm{~min}^{-1}$ for PdII)] of the sample solution. The presented method was also successful for enrichment of $\mathrm{Au}(\mathrm{III})$ and $\mathrm{Pd}(\mathrm{II})$ ions from a large sample volume $(500 \mathrm{~mL})$. Preconcentration of the analytes was not affected in the presence of alkali, alkaline earth, and heavy metal ions. The method can be applied to samples containing heavy metal ions or highly saline samples.

The proposed method provides a simple, accurate, and efficient solid phase extraction of gold and palladium prior to their determination by flame atomic absorption spectrometry.

\section{TABLE VI}

Determination of Pd in Certified Reference Material

\begin{tabular}{lcccc}
\hline Sample & Analyte & $\begin{array}{c}\text { Certified } \\
\text { Value }(\mathrm{ppm})\end{array}$ & $\begin{array}{c}\text { Our Value }^{\mathrm{a}} \\
(\mathrm{ppm})\end{array}$ & $\begin{array}{l}\text { Relative } \\
\text { Error }(\%)\end{array}$ \\
\hline $\begin{array}{l}\text { Platinum Ore } \\
\text { SARM7B }\end{array}$ & Pd & $1.54 \pm 0.032$ & $1.49 \pm 0.04$ & -3.2 \\
\hline
\end{tabular}

\footnotetext{
${ }^{a}$ Average and standard deviation of three determinations.
} 


\section{ACKNOWLEDGMENTS}

This work was supported by Sakarya University Research Fund with Project Numbers 2007.02.04.001 and 2007-50-01-044.

Received July 4, 2011.

\section{REFERENCES}

1. A.G. Coedo, M.T. Dorado, I. Padilla, and F. Alguacil, Anal. Chim. Acta 340(1-3), 31 (1997).

1. A.G. Coedo, M.T. Dorado, I. Padilla, and Alguacil, Anal. Chim. Acta 340 (1-3), 31 (1997).

2. R.R. Barefoot, and J.C. Van Loon, Talanta 49 (1), 1 (1999).

3. B. Salih, O. Celikbicak, S. Doker, and M. Dogan, Anal. Chim. Acta 587, 272 (2007).

4. G.V. Myasoedova, O.B. Mokhodoeva, and I.V. Kubrakova, Anal. Sci. 23(9), 1031 (2007).

T. Ogata, and Y. Nakano, Water Res. 39(18), 4281 (2005).

6. M. Hidalgo,A. Uheida, V. Salvado, and C. Fontas, Solvent Extr. Ion Exc. 24, 931 (2006).

7. B. Godlewska-Zylkiewicz, and M. Kozlowska, Anal. Chim. Acta 539(1-2), 61 (2005).

8. H.B. Senturk,;A. Gundogdu, V.N. Bulut, C. Duran, M. Soylak, L. Elci, and M. Tufekci, J. Hazard. Mater. 149, 317 (2007).

9. H. Zheng, D. Zhang, W.Y. Wang, Y.Q. Fan, J. Li, and H.P. Han, Microchim. Acta 157, 7 (2007).

10. M. Behpour, A.M. Attaran, S.M. Ghoreishi, and N. Soltani, Anal. Bioanal. Chem. 382, 444 (2005).

11. J. Nakajima, M. Ohno, K. Chikama, T. Seki, and K. Oguma, Talanta 79, 1050 (2009).

12. R.F. Orsi, R.G. Wuilloud, and J.C.A. de Wuilloud, J. AOAC Int. 85(6), 1410 (2002).

13. O.D. Uluozlu, M. Tuzen, M. Durali, and M. Soylak, J. Hazard. Mater. 176, 1032 (2010).

14. S. Dadfarnia, A.M.H. Shabani, and E. Kamranzadeh, J. Brazil. Chem. Soc. 21(12), 2353 (2010)

15. N.M. Karaaslan, B.F. Senkal, E. Cengiz, and M. Yaman, Clean-Soil Air Water 38(11), 1047 (2010).
16. I. Timur, B.F. Senkal, O. Kaplan, G Kaya, C. Ozcan, N.M. Karaaslan, and M. Yaman, Atom Spectrosc. 30(6), 191 (2009).

17. M. Imamoglu, and V. Gunes, Instrum. Sci. Technol. 36(1), 105 (2008).

18. G. Kaya, I. Akdeniz, and M. Yaman, At. Spectrosc. 29(4), 150 (2008).

19. Q.X. Zhou,N. Zhao, and J.P. Xiao, Atom Spectrosc. 32(2), 62 (2011)

20. M. Yaman, and M. Ince, At. Spectrosc. 27(6), 186 (2006.)

21. S.A. Zhang, and Z.F. Fan, At. Spectrosc. 32(2), 75-79 (2011).

22. S.G. Ozcan, N. Satiroglu, and M. Soylak, Food Chem. Toxicol. 48(89) 2401 (2010).

23. M.E. Mahmoud, A.A. Yakout, S.B. Ahmed, and M.M. Osman, J. Liq Chromatogr. R. T. 31(16), 2475 (2008).

24. E.M. Soliman, and S.A. Ahmed, Anal Sci. 26(4), 473 (2010).

25. Kara, D. Anal. Lett. 37(14), 3033 (2004).

26. T.P. Rao, S. Daniel, and J.M. Gladis, TrAC-Trend. Anal. Chem. 23, 28 (2004).

27. M. Tuzen, K. Parlar, and M. Soylak, J. Hazard. Mater. 121, 79 (2005).

28. M. Zougagh, J.M.C. Pavon, and A.G. de Torres, Anal. Bioanal. Chem. 381, 1103 (2005).

29. V. Camel, Spectrochim. Acta B 58(7), 1177 (2003).

30. C. Duran, D. Ozdes, A. Gundogdu,; M. Imamoglu, and H.B. Senturk, Anal. Chim. Acta 688, 75 (2011).

31. K. Terada, Anal. Sci. 7, 187 (1991).

32. F.A. Pavan, T.M.H. Costa, and E.V. Benvenutti, Colloid Surface, A 226 (1-3), 95 (2003).

33. F.A. Pavan, I.S. Lima, E.V. Benvenutti, Y. Gushikem, and C. Airoldi, J. Colloid. Interf. Sci. 275(2), 386(2004).

34. F.A. Pavan, S. Leal, T.M.H. Costa, and E.V. Benvenutti, and $\mathrm{Y}$. Gushikem, J. Sol-Gel Sci. Techn. 23, 129 (2002).

35. G.R. Pearson, J. Amer. Chem. Soc. 85(22), 3533 (1963)

36. M. Imamoglu, and A.O. Aydin, Fresen. Environ. Bull. 14, 940 (2005).

37. M. Imamoglu, A.O. Aydin, and M.S. Dundar, Cent. Eur. J. Chem. 3, 252 (2005).
38. N.N. Basargin, M.V. Zueva, Y.G. Rozovskii, and K.P. Pashchenko, J. Anal. Chem. 60(3), 234 (2005).

39. Z.X. Su, Q.S. Pu, X.Y. Luo, X.J. Chang, G.Y. Zhan, and F.Z. Ren, Talanta 42(8), 1127 (1995).

40. D. Jermakowiccz-Bartkowiak, BN. Kolarz, and A. Serwin, React. Func. Polym. 65(1-2), 135 (2005).

41. C.S. Li, C.F. Chai, X.F. Yang, X.L. Hou, and X.Y. Mao, Talanta 44(7), 1313 (1997).

42. A. Tong, Y. Akama, and S. Tanaka, Anal. Chim. Acta 230(1), 179 1990).

43. P. Di, and D.E. Davey, Talanta 41(4), 565 (1994).

44. X.J. Chang, Z.X. Su, D. Yang, B.L. Gong, Q.S. Pu, and S.K. Li, Anal. Chim. Acta 354, 143 (1997).

45. S. Tekin, Preconcentration and speciation of iron by using renewable surface flow injection system (RSFIA). Thesis (M.Sc.), Middle East Technical University, Ankara, Turkey (2003).

46. S. Surdem, On-line preconcentration, speciation and determination of chromium by flame atomic absorption spectrometry (FAAS) and chemiluminescence (CL). Thesis (M.Sc.), Middle East Technical University, Ankara, Turkey (2004).

47. J.S. Lee, and L.L. Tavlarides, Solvent Extr. Ion Exc. 20(3), 407 (2002).

48. J.S. Lee, S. Gomez-Salazar, and L.L. Tavlarides, React. Func. Polym. 49(2), 159 (2001).

49. M.L. Arrascue, H.M. Garcia, O. Horna, and E. Guibal, Hydrometallurgy 71, 191 (2003).

50. Z. Hubicki, M. Leszczyńska, B. Lodyga, and A. Lodyga, Minerals Eng. 19, 1341 (2006)

51. Z. Hubicki, A. Wołowicz, and M. Leszczyńska, J. Hazard. Mater. 159, 280 (2008).

52. L. Zhou, J. Xu, X. Liang, and Z. Liu, J. Hazard. Mater. 182, 518 (2010).

53. A. Wołowicz, and Z. Hubicki, Solvent Extr. Ion Exc. 28, 124 (2010).

54. A. Aydin, M. Imamoglu, and M. Gulfen, J. Appl. Polym. Sci. 107(2), 1201 (2008).

55. P. Liu, Q. Pu, Z. Hu, and Z. Su, Analyst 125(6), 1205 (2000).

56. M.A.A. Akl, I.M.M. Kenawy, and R.R. Lasheen, Microchem. J. 78, 143 (2004). 